\title{
La prensa escrita en manuales de retórica del siglo XIX: deslindes genéricos e ideologías lingüísticas
}

The written press in nineteenth-century rhetorical manuals: generic demarcations and language ideologies

\author{
Elvira Narvaja de Arnoux \\ Instituto de Lingüistica / Universidad de Buenos Aires, Argentina \\ elviraarnoux@gmail.com
}

\section{RESUMEN:}

El desarrollo de la prensa impone que las retóricas del ámbito hispánico, que se multiplican en el siglo XIX destinadas a la educación secundaria pero que constituyen también obras de consulta para la elaboración de discursos públicos orales y escritos, incluyan el tratamiento de los géneros periodísticos. Inicialmente se los integra a la elocuencia política, la prosa didáctica o los textos históricos, ya que no se los puede apreciar en su especificidad, y esta perspectiva se continúa en numerosos tratados posteriores producidos, incluso, a comienzos del siglo XX. Sin embargo, a mediados del XIX, Vicente Fidel López avanza en la reflexión al abordar los tipos de publicaciones -diarios y revistas- y los rasgos de los géneros más destacados que por ellas circulan. Con posterioridad a su obra, diversos tratadistas, sensibles a la importancia adquirida por la prensa industrial y el desarrollo del periodismo de información, amplían el abanico de las secciones que registran y proponen caracterizaciones rápidas de algunas de ellas. En este artículo analizaré esas etapas atendiendo a las ideologías lingüísticas que movilizan, no solo las referidas a la función social de la prensa sino también a los géneros que incluyen en los tratados. Sostendré que el dispositivo normativo retórico, si bien ha servido para pensar la escritura periodística, constituye un obstáculo en la medida en que no considera la práctica efectiva de las redacciones y la importancia que adquiere la figura del lector. A estos aspectos atenderán, en cambio, los manuales de periodismo que se publican desde la última década del siglo XIX.

Palabras Clave: Retóricas, Escritura periodística, Ideologías lingüísticas, Géneros discursivos.

\section{ABstraCt:}

The development of print journalism in the nineteenth century led Hispanic handbooks of rhetoric to deal with journalistic genres. At that time, increasing numbers of Hispanic handbooks of rhetoric intended for secondary school education were being published, and were also used as reference works for preparing oral and written public speeches. At first they were unspecific and dealt with political eloquence, didactic prose or historical texts, an approach that endured in many subsequent treatises, even into the early twentieth century. However, in the mid-nineteenth century, Vicente Fidel López made progress by considering types of publications - newspapers and magazines - and the features of their most outstanding genres. Subsequently, various treatise writers, aware of the importance attained by the industrial press and the development of informative journalism, broadened the range of sections recording and proposing brief characterizations of some of those genres. In this article I shall analyze those stages, focusing on the linguistic ideologies that motivated not only the social function of the press, but also the genres included in the treatises. I shall claim that although the rhetoric normative device served to consider journalistic writing, it constituted an obstacle insofar as it did not consider the actual practice of editorial offices and the importance taken on by the figure of the reader. By contrast, these aspects were considered in the handbooks of journalism published as from the 1890s.

KEYWORDS: Rhetorics, Journalistic writing, Linguistic ideologies, Discursive genres.

\section{INTRODUCCIÓN}

Los manuales de estilo periodísticos son uno de los modos de regular la escritura en los medios gráficos. Estos textos prescriptivos de alcance variado se fueron desarrollando desde fines del siglo XIX, aunque con designaciones más generales como Tratado deperiodismo(Jerez Perchet, 1901) o El arte delperiodista (Mainar, 1906), a medida que la figura del periodista profesional fue remplazando, con el avance de la prensa industrial (Guillamet, 2003), a la del escritor profesional que, entre otras actividades, participaba en el medio. De esos manuales, entre los que incluimos en la actualidad los destinados a las versiones on line, hemos inferido, 
en trabajos anteriores, las representaciones sociolingüísticas que los orientan y las tradiciones discursivas en que se inscriben (Arnoux, 2015; Arnoux, Blanco y di Stefano, 1999). Una de ellas es la tradición retórica, cuya incidencia en el control de la discursividad ha sido decisiva, particularmente desde la ampliación de la enseñanza media en el siglo XIX (Arnoux, 2017a). A lo largo de ese siglo, estos manuales en sus diferentes versiones, de Retórica y Poética a Preceptiva Literaria, regulaban la producción escrita y la oralidad formal (elocuencia) y se ubicaban como referentes obligados para encarar la escritura en géneros propios de la vida pública. Si bien se dirigían en primera instancia a un destinatario estudiantil alcanzaban a otros, particularmente los que trabajaban en la prensa, incluso muchos de los autores de esos textos no eran ajenos al periodismo. Sousa (2007: 74) señala que hasta mediados del siglo XIX, y bastante más tarde para los países ibéricos, la formación de los periodistas europeos se asentaba en la retórica. Del mismo modo, García Galindo (2005), cita la retórica de Miguel García de La Madrid (1817) como una obra de síntesis muy utilizada, algunas de cuyas reflexiones eran útiles para el medio periodístico aunque su autor no se refiriera específicamente a él. Por ejemplo, las indicaciones respecto de la narración histórica, opuesta a la "fingida", pueden aplicarse a los géneros informativos de la prensa. En aquellas se insiste acerca de la importancia del orden y de los datos que deben considerarse - nombres, fechas, lugares, causas y resultados- y de la necesidad de ser preciso y breve.

En esta ocasión, abordaremos las indicaciones acerca de la escritura periodística en una serie de manuales de retórica destinados al nivel medio, producidos en el ámbito hispánico, fundamentalmente en la primera mitad del siglo XIX, pero también haremos referencia a otras retóricas posteriores. Los textos abordados muestran, aunque algo tardíamente, su sensibilidad a la expansión de la prensa gráfica. Describen, entonces, los géneros y estilos que consideran más significativos y establecen una serie de reglas respecto del lenguaje que debe circular por el medio y sobre su cercanía y diferencias respecto del propio de los discursos políticos, didácticos, históricos o literarios. Al hacerlo construyen representaciones de la prensa, algunas de las cuales han tenido una respetable permanencia, y esbozan un dispositivo normativo previo al desarrollo, particularmente en el siglo XX, de los manuales de estilo periodísticos. Si bien conviven en la última etapa con estos, se diferencian notablemente ya que, por un lado, la escritura periodística ocupa en las retóricas un lugar marginal y, por el otro, se busca insertarla, en la medida de lo posible, en el sistema de géneros propio sin atender suficientemente a los requerimientos de una práctica marcada por la producción rápida y los intereses y modos de lectura de un público amplio.

Consideraré, entonces, cómo van entrando los géneros periodísticos en las retóricas, qué aspectos se destacan y las ideologías lingüísticas que construyen acerca de la prensa y de la discursividad propia del medio. Pensamos las ideologías lingüísticas como sistemas de representaciones referidos a objetos sociolingüísticos (géneros, estilos, dialectos, registros, medios de comunicación,...) y a sujetos que intervienen en el espacio del lenguaje (hablantes, periodistas, escritores, lectores,...). Estas ideologías lingüísticas actúan en la reproducción o transformación de las sociedades a la vez que son resultado de procesos económicos, sociales, políticos y tecnológicos. En este caso, abordaremos la larga duración de un siglo en el que se pasa de un periodismo de opinión a uno de información, acompañando el crecimiento de la prensa, sostenido en los avances técnicos propios y en los que facilitan la recepción de las noticias como el telégrafo. Este proceso, con "el incremento de los tirajes, los bajos costos de producción y el redimensionamiento de un público de nuevos lectores" (Rivera, 1998: 7), va haciendo necesaria la figura del periodista profesional y también la del reportero (Ezama Gil, 2014), que suministra informaciones al medio gráfico o a las agencias de noticias que se van desarrollando (Palmer, 1983). Los manuales de retórica se centran mayormente en el periodismo de opinión, por lo cual privilegian los textos argumentativos, pero deben dar cabida progresivamente a los géneros de información e, incluso, en la etapa final, a la publicidad. Por otra parte, no dejan, en los distintos momentos, de reflexionar sobre la función de la prensa en las sociedades democráticas. Sin embargo, al hacerlo, no atienden al paso de una cultura de elites a una cultura de masas, lo que percibirán los manuales de periodismo, que partirán por 
ello del tipo de prosa informativa que circula en el medio, sobre todo desde el último tramo del siglo XIX, y que cuestiona, a su manera, zonas de los dispositivos normativos retóricos.

En este artículo haré primeramente algunas observaciones generales acerca del periodismo y su ingreso en los manuales de retórica. Luego ilustraré la asociación que los manuales hacen con los géneros didácticos y los políticos. Me referiré a Gómez de Hermosilla y a Gil de Zárate, quienes participaron en la actividad periodística -el primero fundó El Censor en 1820 y el segundo colaboró en El Semanario Pintoresco, según consigna Seoane (1992)-. Sus manuales, de 1826 y de 1842 respectivamente, fueron de uso obligatorio en las escuelas en diferentes momentos y sus autores tuvieron una participación pública destacada. Mostraremos cómo la perspectiva didáctica o la política o ambas a la vez son retomadas por otros manuales a lo largo del siglo, qué representaciones refuerzan y cuáles han permanecido en los dispositivos normativos posteriores. Luego, consideraremos cómo cuando se intenta deslindar los géneros y los tipos de publicaciones - diarios y revistas- se amplía el universo de la reflexión retórica respecto del campo. Nos detendremos, entonces, en el primer caso reconocido (como lo señala Salaverría, 1997, en una nota) que es el de Vicente Fidel López en el Chile de mediados del siglo XIX con su Curso de Bellas Letras de 1845. Finalmente, consideraremos retóricas del último cuarto de siglo que, si bien dan cabida a los diversos géneros de la prensa, ofrecen un tratamiento limitado y dependiente del sistema normativo en el que se inscriben, a diferencia de los primeros manuales de periodismo, que atienden a la práctica específica de los redactores y a la figura del potencial lector (Arnoux, 2018). Como cierre haremos algunas reflexiones que tenderán a sintetizar lo dicho atendiendo a ciertos aspectos que nos parece importante destacar.

\section{Periodismo y Retórica}

El siglo XIX es un siglo decisivo históricamente para el periodismo en la medida en que los procesos democráticos desarrollados desde fines del XVIII, con su necesidad de construir una opinión pública, así como el avance de los medios tecnológicos -desde las prensas de hierro e impresoras de cilindros hasta las rotativas- lo activan. Uno de nuestros autores, Barros Arana (1908 [1867]: 252), intelectual chileno y autor de un manual de retórica, se refiere a lo primero:

La prensa periódica no ha alcanzado esta situación [ser un medio de difusión de principios políticos, científicos y literarios además de un resumen de las noticias de cada día] sino en el siglo XIX, y mediante las conquistas de la libertad moderna que ha afianzado más o menos completamente la independencia del escritor y el respeto por las opiniones escritas.

Esta representación de la "prensa libre", como orientadora y legitimadora de las prácticas en el medio desde la perspectiva liberal ha tenido, como sabemos, una larga trayectoria, particularmente durante el siglo XX, y notablemente se desarrolla al mismo tiempo que el oficio de escribir se afirma como una actividad rentable.

La función social de la prensa en la etapa de construcción de los Estados nacionales es amplia. Interviene en la conformación de los imaginarios nacionales ya que estos se asientan, entre otras cosas, en lecturas compartidas. En esto, la ficción novelesca, que adquirió el formato del folletín, tuvo un peso nada desdeñable. La prensa sirvió, además, a la puesta en marcha de instituciones republicanas para las cuales el armado de los posicionamientos político-electorales eran esenciales. Por otra parte, la necesidad de apoyar el progresivo avance de la sociedad industrial imponía la difusión más amplia de los conocimientos que se iban produciendo, en lo que la prensa podía colaborar. Esto podía hacerse efectivo gracias a una extensión de la alfabetización que se impondrá sobre todo en la segunda mitad del siglo XIX.

Aquellos que escribían en los periódicos lo hacían desde matrices genéricas ya adquiridas pero a partir de los imperativos del soporte y de la función social de su práctica iban definiendo nuevos formatos (artículos de fondo, gacetillas, novelas por entrega, impresiones de viaje, crónicas teatrales, artículos de costumbres). Por otra parte, el siglo XIX vivió el proceso, que hemos enunciado antes, de pasaje de la profesionalización del escritor al surgimiento del periodista profesional, lo que deja su huella en los manuales. En estos no solo 
se hace referencia al aspecto lucrativo del trabajo, común a los dos casos, sino también se pasa del elogio al que, entre otras actividades, realizaba esas tareas (escritor profesional) al cuestionamiento del periodista profesional, por el limitado dominio de los temas o, en algunas ocasiones, la endeblez de los escritos o la no adecuación a la normativa propia de la prosa "elevada" (Rodríguez Rodríguez, 2016). Si bien las retóricas reconocen la profesionalización del periodista desvalorizan los resultados de su trabajo: pocos son los textos bien escritos.

También, respecto de los manuales de retórica, recordemos que ellos intervienen en el proceso de disciplinamiento de la discursividad, gracias al continuo deslizamiento, común a los otros instrumentos lingüísticos, de lo descriptivo a lo prescriptivo, y que conforman las subjetividades hablantes proponiendo y naturalizando representaciones acerca de, por ejemplo, modos de encadenar los razonamientos, emociones legítimas y desechables, admisión o no de la objetividad o de la subjetividad lingüísticas, modos de relacionarse con el lector o el auditorio. Modelan así la producción discursiva de una época y establecen jerarquías según la mayor o menor adecuación a las normas.

En ese marco, una pregunta que se reiteran los investigadores es cuál fue el tratamiento de los géneros periodísticos por parte de estos instrumentos lingüísticos que daban cuenta de las prácticas discursivas a la vez que las modelaban. Es decir, cómo los manuales de retórica, que se multiplicaron en el siglo XIX destinados fundamentalmente al nivel medio de enseñanza pero que constituían, recordemos, un texto de consulta para los escritores, registran progresivamente los géneros propios del aparato prensa. Se señala que, por un lado, ingresan tardía y erráticamente en la primera mitad del XIX y más decididamente en la segunda mitad (Rodríguez Rodríguez, 2009). Y, por otro lado, se releva que lo que es designado como artículo periodístico aparece asociado inicialmente a los géneros didácticos y a los políticos (García Tejera, 2006; Mancera Rueda, 2011), en la medida en que la prensa informativa se está desarrollando y la diferencia opinión / información se va a marcar más tarde (García Galindo, 2005).

La inclusión de los géneros periodísticos implicaba legitimarlos y hacerlos ingresar en el sistema de géneros, que si bien se abría a las nuevas prácticas lo hacía a partir de clasificaciones ancladas en una extensa tradición (Morales Sánchez, 2000). Las categorías establecidas (como la elocuencia deliberativa) o las que adquirían importancia con los cambios en el sistema educativo y la expansión de la cultura letrada (como la prosa didáctica) facilitaban su inclusión pero podían funcionar también como obstáculos para considerar los discursos periodísticos invisibilizando géneros que si bien se desplegaban en la prensa no podían ser pensados en su autonomía (como, por ejemplo, la novela de folletín aunque ya hubiera ingresado la novela en los manuales de retórica y adquirido una importancia destacable; o la crónica como otro de los géneros narrativos a pesar del desarrollo del tratamiento del discurso histórico y de las observaciones acerca de la objetividad y de los modos como podía expresarse la propia opinión en relación con los hechos que se narraban; o la noticia en su especificidad informativa). Estas dificultades para el reconocimiento de los géneros propios de la prensa se evidencia, por ejemplo, en Monlau (1842: 193), quien participó también él en la prensa (Seoane, 1992). Este tratadista vincula los textos informativos a los géneros históricos ("Los periódicos diarios pueden considerarse bajo cierto aspecto como anales locales del pueblo o provincia donde se publican") y las notas de opinión a los didácticos ("la parte doctrinal de los periódicos pertenece de algún modo al género didáctico").

\section{El ARTÍCULO PERIODÍSTICO ENTRE LO DIDÁCTICO Y LO POLÍTICO}

Cuando se hablaba de los géneros periodísticos (ya que textos como el de Munárriz (1815), Herrera Dávila (1827) y Avendaño (1885 [1844]), por ejemplo, no lo hacían) dos fueron, fundamentalmente, como ya lo hemos señalado, los ámbitos en los que se los inscribía - la prosa didáctica o la elocuencia política- ya que en ellos dominaba el despliegue argumentativo privilegiado tradicionalmente por la retórica. Esto va a implicar que los primeros manuales se centren globalmente en el artículo periodístico argumentativo y valoren lo que designan como el "artículo de fondo". De la inclusión en el campo didáctico posiblemente 
devenga la representación del magisterio de la prensa respecto de la sociedad, que ha tenido una destacable permanencia, particularmente en el siglo XX. En cambio, la pertenencia al campo de los escritos políticos va a ser desechada, en ese mismo siglo, cuando se imponga el imaginario de la prensa informativa ajena a la disputa partidaria, sometida solo a la verdad de lo que se refiere y destinada a un público heterogéneo. Pero en el período que consideramos se afirma y da lugar al reconocimiento del carácter polémico y político del escrito periodístico, y a la aceptación del apasionamiento discursivo, aunque con las limitaciones, como veremos, que la educación y las buenas costumbres imponen.

De la inclusión del periodismo en lo didáctico o en lo político son testimonios en la primera mitad del siglo XIX, como adelantamos al comienzo al referirnos a los autores, el Arte de Hablar en prosa y verso de Hermosilla (1841 [1826]) y el Manual de Literatura. Principios generales de Poética y Retórica de Gil de Zárate (1842). Ambos tuvieron una gran difusión en el ámbito hispánico y fueron, en diferentes momentos, libros de texto impuestos por las autoridades educativas españolas para el nivel medio así como poblaron las bibliotecas hispanoamericanas, lo que les permitió llegar a un público amplio. Sus autores, además, eran reconocidos en el espacio intelectual, en la actividad periodística y en la función pública.

El primero introduce (1841: 347) "los artículos literarios" insertos en los periódicos (entendidos en un sentido amplio como ensayos de poca extensión) dentro de los tratados sueltos sobre objetos de ciencias y artes. Considera aquellos un tipo de "disertaciones", y estas están comprendidas en las obras didácticas junto con los tratados magistrales y los elementales. Piensa en textos razonados que enfocan problemáticas particulares que tengan cierta actualidad y prestigio social. La importancia de lo argumentativo se evidencia cuando se refiere, al hablar de las disertaciones, a las figuras:

Las formas que convienen a las composiciones didácticas son las llamadas de raciocinio, señaladamente los símiles ilustrativos y los ejemplos tomados de los hechos y caracteres de los hombres $(348)^{1}$.

Las normas para los artículos son comunes a todas las disertaciones: no olvidar el estilo (recomienda una "moderada elegancia”, el más alto grado de "claridad y precisión") y prestar atención a la corrección del lenguaje.

La legitimación del periodismo se da, entonces, en este caso, por la vía del discurso argumentativo y por la función didáctica valorada en tanto lo es la difusión de los conocimientos.

El vínculo del artículo periodístico con la disertación se va a reiterar en manuales que se publican en la segunda mitad del siglo XIX. Por ejemplo en el de Rodríguez (1879: 111), profesor del colegio Monserrat de Córdoba (Argentina) que opta por la dimensión didáctica e incluye asimismo los artículos periodísticos dentro de las disertaciones:

A esta clase de trabajos se refieren también los discursos académicos de recepción, las revistas cientificas de los diarios o periódicos, y aun los artículos literarios y de costumbres insertos en estos, con tal que versen sobre un punto o tópico determinado de alguna ciencia o arte $^{2}$.

Gil de Zárate, en cambio, privilegia la dimensión política, importante en una etapa de desarrollo de la prensa partidista, e incluye los artículos periodísticos en la elocuencia moderna. La legitimación, en este caso, proviene de que son una de las formas del espacio nuclear de la retórica como es el de la elocuencia:

Ramo, y no poco importante, de la elocuencia política moderna son los periódicos, cuyos artículos llamados de fondo no son en realidad más que unas arengas que un particular dirige todos los días a una multitud de personas esparcidas en toda la superficie de un estado. (199)

Podemos destacar la mirada hacia el periodista como al de "un particular", aludiendo, por un lado, a cierto anonimato y, por el otro, a que no es un personaje socialmente reconocido. Es un esbozo del ideal de "periodismo ciudadano" (Espiritusanto y Gonzalo Rodríguez, 2011), que si bien desaparece con el periodista profesional, en el siglo XX, se manifiesta otra vez en nuestros días apoyado en las nuevas tecnologías. En este 
caso una vieja representación se activa gracias a condiciones que lo hacen posible y su valoración ancla en la que ya se había naturalizado en una etapa anterior de expansión de la circulación de información.

Esta asociación del periodismo con la elocuencia política va a permanecer a lo largo del siglo. Cortejón (1890), por ejemplo, copia lo señalado por Gil de Zárate. Coll y Vehí (1894 [1862]), por su parte, destaca la condición de efímero que lo acerca a las producciones orales:

La elocuencia militar y la periodística pueden considerarse como dos ramas de la oratoria política. La militar, enérgica y concisa, rehúye toda clase de artificio, impropio de los campos de batalla: simpliciora militares decent. Los artículos políticos de los periódicos, escritos para ser leídos hoy, y olvidados mañana, emplean formas enteramente oratorias, y pueden considerarse como una ligera modificación de los discursos parlamentarios.

Hay tratados que lo asocian con la elocuencia popular aunque reconozcan la diferencia que instaura la falta de oralidad. Así Verdaguer y Callis (1889: 71) afirma:

Algunos consideran como rama de la oratoria política los artículos de periódicos, acogiéndoles como legítimos sucesores de las antiguas arengas populares, de las cuales han heredado la vehemencia y la pasión; fáltales, sin embargo, la vida de la pronunciación, verdadero distintivo de la oratoria.

También Gil de Zárate considera a los artículos periodísticos herederos de aquella y cuestiona los rasgos que comparten:

Aquí se permite un escritor, lo que como orador no se atrevería a decir en el parlamento: aquí se entrega a toda la fogosidad de sus pasiones, a lo avieso de sus rencores, a las malas instigaciones del espíritu de partido, a las acriminaciones más sangrientas y aun a los insultos más groseros. (200)

Para muchos autores el periodismo debe desprenderse de los rasgos de la elocuencia popular para acercarse al discurso parlamentario surgido de las nuevas instituciones representativas. Este debe ser el modelo de la prensa en la medida en que tiende a ser un discurso entre iguales, que es como se piensa al lector del periódico aunque se reconozca la amplitud y heterogeneidad del público.

Así como la elocuencia popular oral propia de los demagogos debe ser remplazada por el debate parlamentario entre iguales (que integran el espacio de la "gente decente"), la prensa debe hacer lo mismo: "el periodismo va [debe ir, si consideramos el continuo deslazamiento de lo descriptivo a lo prescriptivo] adoptando las formas de la buena discusión parlamentaria, aunque siempre con más calor y vehemencia”.

El artículo periodístico es visto, así, como partícipe de la vida política, de allí la admisión del apasionamiento aunque con urbanidad. Representaciones posteriores de la prensa surgidas de los manuales específicos producidos desde fines del siglo XIX y comienzos del siglo XX van a ir desechando, como dijimos, esa marca de subjetividad (lingüística), en relación sobre todo con la noticia, debido a la aspiración a la objetividad y el privilegio otorgado al estilo impersonal (Salaverría, 1997). Este cambio se debe a que la prensa, en sus desarrollos posteriores, tiene que alcanzar cada vez más a un público amplio, no el meramente partidario, para aumentar sus ventas. En la etapa inicial del medio, a este requerimiento económico no se atendía tanto y la composición del público incidía sobre todo en la norma reiterada de una mayor claridad expositiva, brevedad y sencillez (preocupación común en esta etapa pero que se exacerba, notablemente, con los digitales, que participan en una nueva expansión de la cultura escrita).

La prescripción atiende a las normas de urbanidad propias de la sociedad burguesa. Gil de Zárate insiste desde la posición de los sectores dominantes:

Para esto [para alcanzar el modelo de la elocuencia parlamentaria] no hay más reglas que recomendar que las que convienen a una polémica urbana y decorosa, fundada en la solidez de las doctrinas, en lo profundo y escogido de los argumentos, en la templanza del estilo, y en el respeto que se deben guardar los hombres de educación unos a otros, ora se hablen cara a cara, ora se oculten bajo el nombre de un editor responsable. (200)

La práctica periodística va a ser modelada por estas representaciones que construyen los manuales y se va a naturalizar el despliegue de un discurso razonado en un estilo adecuado en el que la polémica, que se acepta, 
no debe dejar de lado lo que las buenas costumbres imponen. También en este caso, las normas de escritura periodística para los medios digitales van a volver sobre ello en sus manuales de estilo con la insistencia en lo políticamente correcto y en la "netiqueta" (la etiqueta en la red).

Diego Barros Arana (1908 [1867]: 248-250), por su parte, si bien justifica lo pathémico ("los escritos del periodista lanzados en medio de su lucha, deben participar del calor de esta"), señala los límites: "no es posible abandonar el terreno de la fría razón [...] conviene que el periodista se dirija más a la inteligencia que al sentimiento"; "el escritor debe estar convencido de lo que dice"; "tampoco le es permitida la exageración, la destemplanza, la procacidad para con sus adversarios". Y en relación con las polémicas en las que intervienen los periódicos plantea: "si el periodista no puede en ocasiones sustraerse a este género de debates, no debe olvidar que la fuerza de raciocinio hace más impresión cuando va envuelta en el ropaje de la templanza y de la moderación". La dimensión ética que se destaca respecto del ejercicio del periodismo se articula con el control de las emociones al que tienden los tratados de retórica y urbanidad del siglo XIX (Arnoux, 2017).

López de Vergara (1858) se preocupa por articular más detenidamente la función social que le asigna a la prensa con los rasgos discursivos. Dedica un apartado a "la elocuencia de la prensa periódica" en el que la valora por su función en los sistemas representativos ("constitucionalmente hablando no se puede concebir, ni un momento, un gobierno representativo sin este poder", 279) ya que es un auxiliar de la libertad política, una herramienta contra la arbitrariedad y un complemento de esa misma práctica:

En ellos [los artículos de fondo] se combate con firmeza lo que en el Parlamento quizás pasó desapercibido; o en lo que no fue permitido a los Diputados o Senadores insistir, por haber sido llamados al orden, o interrumpidos por causas que no pudieron remover. (278)

La prensa alcanza a un público amplio que puede no solo informarse acerca de lo dicho en los órganos representativos sino también reflexionar críticamente a partir de los escritos:

Miles de ejemplares circulan por todas partes, y de esta manera los que no se hallaron en la sesión, o los que alucinados por el brillo de una improvisadora alocución, creyeron útil lo que envolvía un daño positivo, quedan desengañados, leyendo con meditación en los periódicos, todo cuanto es relativo al punto de la cuestión. (278-279)

Sin embargo no deja de señalar los peligros si no se actúa con prudencia y se la usa para "saciar resentimientos de partido". En esos casos el abuso debe "sufrir la pena que le imponga la ley vigente, sobre libertad de imprenta" (279). El abuso puede expresarse en la exaltación de pasiones, que lleva a olvidar el necesario decoro. Como en otros manuales se plantea la exigencia moral de respeto al otro y el mandato de un debate público entre "hombres ilustrados al mismo tiempo que finos y delicados en las discusiones" (280), como debe ser la norma particularmente en las situaciones políticas ya consolidadas. Si bien los debates en la prensa pueden ser "fuertes y animados", lo fundamental es el peso de la argumentación (el discurso además de vehemente debe ser razonado):

Se procurará dar toda la solidez conveniente a los razonamientos, que sirvan para demostrarnos una verdad política; y con urbanidad se refutarán los argumentos, que se opusieren en contra. De esta manera el convencimiento que tiene por objeto el artículo de fondo será mayor. (279)

Como vemos las reglas exceden, en general, el campo de la escritura, se desplazan fácilmente al ámbito moral, y esto sostiene la representación persistente de una "ética del periódico" construida históricamente gracias a estos segmentos en los que los manuales de retórica reflexionan respecto de la dimensión pathémica de los escritos.

El desarrollo del medio impone su ingreso al manual pero esto no puede hacerse fácilmente ya que los géneros no están totalmente consolidados en las prácticas y son vistos como expresiones particulares de las producciones verbales ya reconocidas, de las que se diferencian por el modo de difusión que tienen. De allí que se insista en que las reglas establecidas pueden aplicarse también a este ámbito y que la especificidad deriva 
de rasgos de producción del medio como son la brevedad, la necesidad de rapidez, lo efímero de su vigencia o la necesidad de alcanzar a un número amplio de lectores.

En relación con los géneros en los que se apoya la escritura periodística, también se incluye el histórico. Barros Arana (1908 [1867]: 247) señala:

El periodismo, es decir, los artículos que publican los diarios y periódicos, no forman en realidad un género literario separado de los otros que acabamos de analizar en los capítulos anteriores. Los artículos periodísticos tienen por objeto o discutir un principio, o generalizar nociones científicas, políticas o literarias, o referir hechos, ya sea que se cuente un suceso o se escriba la biografía de un personaje. En todos estos casos los escritos a que nos referimos pertenecen propiamente al género didáctico o al género histórico.

Remite a las reglas del discurso histórico que el periodista deberá aplicar parcialmente en sus crónicas y sobre todo en la narración de la noticia. La tensión entre lo conocido y lo nuevo se muestra en que si bien se señala la dependencia de los géneros consagrados se recorren las peculiaridades de los despliegues periodísticos.

La mirada desde lo didáctico y lo político, y en algunos casos lo histórico, se mantiene a lo largo del siglo, sobre todo por parte de aquellos que no le dedican al discurso periodístico un tramo de cierta independencia. Sin embargo, incluso estos, remiten en muchos casos a esas representaciones. Así, Campillo y Correa (1875 [1872]: 186) se centra en el artículo de fondo, altamente valorado en la etapa del escritor profesional y de la prensa de opinión. Señala primero la especificidad de que es escrito y por lo tanto debe tener mayor exactitud y de que es efímero y por lo tanto se le pueden admitir ciertas incorrecciones de lenguaje. Incluye los "artículos doctrinales publicados en los periódicos" dentro de las disertaciones y monografías y les asigna las mismas normas que a estas:

[...] Respecto del lenguaje y estilo, además de la claridad, precisión y nobleza propias de toda obra didáctica, puede tener no escasa riqueza y elevación en algunos asuntos; mas generalmente debe distinguirse por la corrección de formas y esa elegancia sencilla que tan bien sienta a la verdad, haciéndola comunicable y amena

La permanencia del saber retórico se consolida en los diversos retomes que se hacen y que encontramos en los últimos exponentes del período estudiado. Por ejemplo, un manual de comienzos del siglo XX, el de Frumento (1900), retoma lo de Campillo y Correa. Castañeda (1916 [1892]: 164-165) también señala las dos posibilidades de artículos periodísticos. Por un lado, los que se aproximan a la oratoria política. En ese marco ubica los "artículos de fondo" o "editoriales": "aquel escrito que, versando sobre un asunto general y de importancia es como la expresión de las ideas que caracterizan e imprimen fisonomía moral al periódico". Por otro lado, incluye los "artículos doctrinales de los periódicos" dentro de la categoría de "disertaciones" a las que les otorga los siguientes rasgos:

[...] El lenguaje de esta clase de escritos debe ser claro correcto y elegante, como el de todas las obras didácticas; y su estilo sencillo o elevado, cortado o difuso, según los pasajes; pero nunca florido, pues este es incompatible con la naturaleza de dichas obras.

Otra retórica tardía, la de Jarrín (1893: 180-181), interesante porque reconoce, como veremos en el apartado 5, la crónica al mismo nivel que el artículo de fondo, va a introducir nuevamente la distinción entre oratorios y didácticos. Estos últimos están sometidos a las mismas reglas que otras composiciones didácticas. En cuanto a los oratorios, "son una modificación de los discursos parlamentarios y comprenden un asunto cuestionable, en que cabe el pro y el contra, originando la polémica”. Como tienen por fin la persuasión, "admiten calor, y su elemento más propio son las pasiones, aunque subordinadas a la convicción y procurando el agrado".

Y no deja de lado tampoco la valoración moral: 
Cuando las cuestiones se ventilan en el terreno de los principios, es menester que estos sean fijos, y que las consecuencias se deduzcan lógicamente; pero cuando se desciende al terreno de las personas, se hace preciso guardar al adversario las consideraciones y miramientos que exige la buena educación, en conformidad con los preceptos de la moral. (181-182)

Como vemos se retoman las representaciones asociadas con el artículo periodístico desde los comienzos de período analizado. Esto muestra la notable estabilidad del saber retórico que, si bien da cabida al periodismo, necesita, a lo largo del siglo XX, vincularlo con los espacios discursivos conocidos.

\section{Hacia el reconocimiento de la especificidad del Periodismo: Vicente Fidel LÓPEZ}

Para poder reconocer lo propio del medio es necesario ser sensible a la diversidad de publicaciones y géneros y no quedarse ni en la vaga representación del artículo ni en destacar el parentesco de algunas expresiones periodísticas con otros géneros ni reducirse a los rasgos estilísticos reconocidos. En Chile, Vicente Fidel López, cuyo sistema retórico va a integrar expresiones como la clase, el mensaje del ejecutivo o la memoria ministerial (Arnoux, 2008), avanza en ese sentido en su Curso de Bellas Letras (1845) no solo haciendo entrar otros géneros periodísticos e intentando su caracterización sino también explicitando las diferencias entre revista, diario y libro y las particularidades de los escritos según esos espacios.

Esto es posible porque, por un lado, valora el medio ya que no solo reconoce el peso de la prensa cotidiana en las sociedades modernas, como lo hacían los otros autores, sino que también considera el trabajo en el periódico, a lo que él no era ajeno:

Tal es hoy el poder de la prensa cotidiana que hasta los tiranos mismos tienen que valerse de ella como de un medio de gobierno; sería tan absurdo negar la utilidad general de esta acción como injusto desconocer el talento que despliegan y consumen nuestros contemporáneos en los ingratos trabajos que ella exige. (206)

Como vemos se la asocia con las nuevas prácticas políticas en las que la opinión pública es un aspecto nada desdeñable y que se impone en regímenes liberales como en dictaduras. Por otra parte alude, en cierta medida, a la profesionalización del escritor ya que este no solo debe tener el talento para desempeñarse sino que debe ser capaz de realizar "los ingratos trabajos que ella exige", probablemente por la rapidez que debe dar a la producción del texto y la poca permanencia del mismo.

Pero también López reconoce lo que implica como práctica con el lenguaje, las condiciones en que esta se realiza y su función particular en las sociedades hispanoamericanas. Así, en una nota señala que "el diario entre nosotros hace a la vez el papel de Libro, de Revista y de Diario" en parte porque es "una publicación más fácil y ligera”, pero también porque es "la única que proporciona algún lucro" (en lo que aparece, desde otro lugar, el tema de la profesionalización del escritor). Asimismo, explica lo que le parece propio de estas latitudes: la necesidad de "publicaciones más serias y meditativas" y las dificultades para responder a ella. Dice así:

[...] es difícil y dispendioso llevar al cabo publicaciones voluminosas; los hombres de luces y de talento que las pudieran realizar difícilmente tendrán tiempo para meditarlas y desenvolverlas, porque la escasez de hombres es grande todavía y la acción arrebata todos los que pudieran dedicarse con fruto a la meditación. (203)

De allí que no solo señale las diferencias ligadas a la forma material del producto (libro, revista, diario) sino también en cómo ella incide en las respectivas discursividades y destaque que el diario en Hispanoamérica tiene un perfil propio, algo híbrido, porque por razones histórico-sociales cumple la función de los otros dos incluyendo reflexiones de un alcance mayor que lo que se juzga habitual. A lo que agrega un dato más que tiene que ver con los que ejercen el periodismo: son intelectuales comprometidos con "la acción", a los que por un lado el medio les facilita la posibilidad de expresarse ("no hay hombre influyente que no esté obligado a dar publicidad a sus doctrinas”, 202) pero limita el desarrollo detenido al que, por otra parte, no pueden 
dedicarse. López al esbozar la complejidad de la práctica muestra la necesidad de abordar el periodismo en su especificidad que no solo es discursiva sino social.

El reconocimiento de las condiciones sociales de la práctica le permite hacer deslindes genéricos. En primer lugar, incluye artículos de revistas y artículos de diarios, con sus peculiaridades propias, dentro de los trabajos de crítica. Jerarquiza el diario y la revista al ponerlos al lado del libro, que es el tercero de los modos como se pueden presentar los trabajos de crítica. Es decir que reconoce los diferentes formatos y se propone definir sus especificidades. Valora el artículo de revista ya que "llena el vacío que necesariamente había antes de ellas entre las teorías y su aplicación a las grandes necesidades de una época”. Lo caracteriza contrastándolo con el libro. Por ejemplo dice: el artículo "debe descomponer las cuestiones para examinarlas en sus detalles dejando al libro que las abarque todas para discutirlas en su totalidad". En él intervienen, además, "los escritores y hombres públicos más célebres de nuestros días" (202). Así sintetiza:

Un artículo de revista es un trozo literario en que se aprecia algún hecho, alguna cuestión, con una regular extensión creando sobre ella una teoría que la ponga en relación con las necesidades y problemas de la sociedad contemporánea. (201)

El objeto de la revista es discutir las verdades de aplicación con preferencia a las verdades absolutas; no poniendo en olvido el examen de estas últimas, sino poniendo en mayor relieve el de las primeras. (201)

Cuando se refiere al estilo alude a tres modalidades discursivas que puede adoptar o que "debe dominar": "el filosófico o analizador propio de las obras de Estética; el narrativo, propio de las obras de Historia, este es el más rico y lujoso [pensemos que López se va a destacar como historiador]; y el dogmático, propio de las obras de Retórica” (202). Son, como vemos, modalidades discursivas de un género, el artículo de revista, que tiene sus rasgos propios y no, como se visualizaba en otras aproximaciones, como escritos de otros campos que encontraban su lugar en el medio gráfico.

Admite la dimensión polémica de estos escritos pero señala que "nunca este debe hacerse notar tanto que tiña el escrito con las pasiones y los intereses exclusivos solo del día y de la cuestión” (202). En eso se diferencia del artículo de diario.

Como considera que el artículo de diario es "un escrito destinado esencialmente a discutir los intereses políticos" (202) desplaza su tratamiento al tramo en el que se dedica a los escritos políticos, aunque acepte que pueden aparecer artículos de otro tipo, literarios por ejemplo, que van a ser próximos a los de las revistas. Le asigna a aquel los siguientes rasgos generales ya que considera que en el género influyen fuertemente las características del escritor, el partido, la época o el país (en lo que evidencia una vez más su sensibilidad a las condiciones de producción de los textos):

El artículo de diario debe mostrar la apariencia de una improvisación sagaz y penetrante, inspirada por las necesidades e intereses del momento; está pues alejada de él toda investigación seria y paciente de las teorías científicas: su objeto es la aplicación de los principios dominantes y generalizados en la opinión pública a los medios de gobierno; aplicación inmediata y detallada, cual la requieren las necesidades y los intereses diarios de las naciones. (206)

El artículo de diario puede centrarse en otras cuestiones más allá de las políticas. Habla entonces de dos géneros que se acercan al ensayo o a la novela: los artículos de fondo, objetos privilegiados de la retórica cuando se refiere al periodismo, y los folletines. En relación con el primero plantea que

[...] aspira siempre a vestirse con las cualidades del artículo de revista, es decir; procede con cierto orden y elevación en la discusión de los principios, subiéndose en lo posible a las generalidades teóricas, y empleando un estilo razonador en cierto modo, pero ligero, apasionado y fácil como conviene a las cuestiones cotidianas y menudas que ocupan la vida de una publicación como esta, que jamás debiera proponerse la discusión profunda de los temas abstractos de la ciencia. (203)

Por su parte, el folletín (asociado en general al texto "por entregas") se propone no la instrucción sino la amenidad del lector y puede ser de dos clases, crítico o novelesco:

El primero es aquel que se contrae a despertar el buen gusto o el sentido común del lector, y que se propone dirigir su juicio en las cuestiones literarias. El segundo es una verdadera novela, un cuento de imaginación. (203) 
La valoración del tratamiento de lo literario, particularmente lo novelesco, en el periódico es negativa, aunque él va a incursionar en la novela popular histórico didáctica como La novia del hereje o La loca de la guardia: "no solo le ha robado nobleza sino que ha rebajado en extremo su dignidad: la política tiene mucho que agradecerle, pero la literatura no le debe por cierto servicio alguno” (203). Cuestiona así, aunque las integre al abanico retórico, las formas narrativas de consumo popular en formato periodístico.

Cuando habla del folleto como un escrito mediano con unidad temática, y con carácter polémico lo que da lugar a un estilo "apasionado, ardiente y vigoroso" (205), propio de las prácticas que el periodismo inaugura, se refiere en particular a la "diatriba contra una cosa o una persona cualquiera, y que no es polémico por no haber defensor conocido de esa cosa" e ilustra con los artículos de Larra, muy leído y apreciado en el Chile de esa época, es decir que parece considerar lo que se va a definir como el "artículo de costumbres".

Así, López, desde su lugar de intelectual hispanoamericano que publica en la prensa de su época, reflexiona sobre los tipos de publicaciones -diarios y revistas- destacando sus diferencias y tratando de deslindar genéricamente los escritos más destacados que en esos espacios se producen.

\section{El recorrido por los géneros periodísticos en el último tercio del siglo XIX y los comienzos del XX}

La especificidad del periodismo va a seguir abriéndose lugar, lenta e irregularmente, en los manuales de la segunda mitad del XIX. Barros Arana (1908 [1867]: 247), por ejemplo, si bien considera, como dijimos, que los escritos periodísticos pertenecen al género didáctico o histórico, admite: "el periodismo discute los principios, generaliza las nociones y cuenta los hechos de una manera tan particular, que casi puede decirse que exige preceptos especiales o, a lo menos, una modificación parcial de los preceptos generales". Si bien a lo largo del siglo muchos manuales insisten en la pertenencia del artículo periodístico a los campos conocidos y privilegian el "artículo de fondo", asociado con la prensa de opinión, otros van pensando en los nuevos géneros que habitan el aparato prensa, diferenciando diarios y revistas, como lo hacía López, y reconociendo la crónica, aunque en este caso su caracterización sea vacilante.

Nos referiremos a algunos autores que tratan de abordar lo propio de la prensa y van introduciendo en forma de enumeraciones y comentarios breves distintos tipos de discurso o haciendo deslindes en el archigénero "artículo periodístico".

Arpa y López (1878: 164) parte del artículo, es decir, "aquel escrito que se destina para ser publicado en diarios, periódicos, revistas y otras publicaciones de índole análoga”. La división en géneros se debe, según este autor, a que las materias que trata son muy diferentes, aunque al describir cada uno señale las diferencias de estilo según los modos de leer el artículo o remita a los géneros retóricos de los que a su criterio dependen. Registra las denominaciones de época y no adopta un criterio sistemático: en el caso de "revistas" privilegia el objeto, no el género; en el de "polémica" la actitud o el alcance, y en los literarios posiblemente su carácter ensayístico que implicaba una prosa más cuidada. Así enumera los diferentes tipos de artículos: "artículos de 'fondo, literarios, de costumbres, críticos, revistas, folletines, comunicados, de polémica y gacetillas".

Realiza, por otra parte, un esfuerzo descriptivo que le permitirá enunciar con mayor o menor precisión y extensión las reglas. Si bien estas son bastante generales y reiterativas y corresponden globalmente a la representación que se tiene del periódico, demuestran un interés por reconocer especificidades y diferencias entre los géneros y cierta sensibilidad al paso a los periódicos de información. Ilustraremos con las gacetillas, que son "las noticias, al parecer ligeras, que se dan en la última parte del periódico sobre los acontecimientos más importantes del día”. En tipografía menor señala su importancia y vislumbra lo que será el lugar que ocupará la noticia en la prensa gráfica y su incidencia en la ampliación del público lector: 
Decimos al parecer ligeras, por ser trabajos cortos y de pocas pretensiones literarias; mas si se tiene en cuenta el afán y curiosidad con que se devoran generalmente esas noticias y comentarios, se comprenderá que en realidad tienen más importancia de lo que a primera vista aparece. (167)

En cuanto a las reglas del género establece que "como exposición de un hecho o noticia, deben ser narradas con suma claridad y sencillez; y respecto a su comentario, debe ser este muy cuidadosamente acertado y justo". Sin embargo, advierte desde una posición ética, que la mayoría de los manuales no abandona:

Tal vez no haya nada más a propósito a la larga para falsear el juicio, lo mismo sobre cosas que personas, que esa sección periodística. ¡Cuántas reputaciones inmerecidas no contribuye a levantar, y cuántas precoces inteligencias no detiene en su camino cuando se abusa de ella!

Al artículo de costumbres se refiere Arpa y López (166), un año antes de que aparezca simplemente enunciado en Rodríguez (1879), pero va a ser tratado con mayor detenimiento, y prácticamente como el único al que se atiende de los géneros periodísticos, en un texto tardíamente difundido, el de Marroquín (1935 [1882]), que lo define como obra de imaginación perteneciente al género narrativo, de extensión reducida y cuya finalidad es "la pintura o al vituperio de una costumbre". Le asigna una función de testimonio ("pintar, para instrucción de los extraños y de la posteridad, las costumbres de los países en épocas determinadas") y una función didáctica ("corregir lo vituperable o defectuoso que haya en dichas costumbres”). Morales Sánchez (1999) destaca que Marroquín relaciona directamente el artículo de costumbres con una nueva forma de las "historias ficticias" que reconocían las retóricas, diferente del cuento o de la novela. En ese sentido, el tratadista plantea:

[...] Un artículo de costumbres es la narración de uno o más sucesos, de los comunes y ordinarios, hecha en tono ligero y salpicada de observaciones picantes y de chistes de todo género. De esta narración ha de resultar o una pintura viva y animada de la costumbre de que se trata, o juntamente con esta pintura, la demostración de lo malo o de lo ridículo que haya en ella; mas esta demostración han de hacerla los hechos por sí solos, sin que el autor tenga que introducir reflexiones o disertaciones morales para advertir al lector cuál es la conclusión que debe sacar de lo que ha leído.

El comentario revela lo que se va imponiendo en la prensa: dejar el análisis para determinadas zonas, cada vez más restringidas, y preocuparse por orientar argumentativamente al lector gracias al modo de referir los hechos, lo que va a manifestarse fuertemente en el despliegue de la noticia.

Francisco Jarrín (1893), por su parte, valora el periodismo en un final de siglo en que su peso social es indiscutible y en que llega a un público más amplio. Por un lado, reconoce como rasgos la sintesis, la variedad y la popularidad: "La primera, porque resume todos los géneros literarios; la segunda porque abraza materias heterogéneas; y la tercera porque se dirige principalmente a difundir la cultura entre el pueblo" (180). Tercia, por otro lado, en una nota (180), en la polémica existente entre la aceptación y el rechazo al medio, inclinándose por la primera siempre que se asuman los valores sociales que destaca:

Para unos la prensa periódica es un apostolado, y para otros, la lepra de las sociedades modernas. Cierto que de nada se ha abusado tanto como del periódico; pero el abuso no basta para condenarle. La palabra, hablada o escrita, es un arma ofensiva y defensiva: en manos del malvado es un instrumento de perversión; en manos de un hombre honrado, es el medio de promover el órden, de afianzar la justicia y de amparar la religión.

Deslinda claramente periódicos y revistas. En relación con los primeros, clasifica los géneros en dos grandes categorías: artículos, a los que denomina siguiendo una larga tradición artículos de fondo, y crónicas. Divide los artículos en literarios y políticos y se centra en estos últimos. Señala que el periódico político (que puede tratar de "política interior, exterior o internacional") "es un órgano del respectivo partido y, por lo tanto no responde sino a la opinión de sus adeptos [...] podrá sin embargo modificarla dirigiéndola con acierto, en cuyo caso influirá en la dirección de la opinión [pública] para bien de la patria” (182). Como su perspectiva parte de la prensa de opinión, vuelve así a las persistentes representaciones sobre lo didáctico y lo oratorio, que habíamos señalado en el apartado 3. 
Lo interesante es que cuando se refiere a otras partes del periódico también se preocupa por la remisión a los campos conocidos: "los comunicados se conformarán con las reglas sentadas para el género epistolar"; los folletines se conformarán con las reglas del género respectivo". Incluso insiste en las normas retóricas generales: "las condiciones generales de la elocución, y las especiales del género, se imponen a todo escritor" (184). Jarrín no puede alejarse del aparato retórico como sí lo harán los manuales de periodismo posteriores interesados por la especificidad del campo desde el lugar de la práctica.

Si bien no escapa a la dependencia de las representaciones anteriores, es uno de los primeros (Mancera Rueda, 2011) en valorar la crónica ya que la pone al mismo nivel que el artículo de fondo. La subdivide según los ámbitos a los que se refiera, por ejemplo, crónica religiosa o política o por su alcance (local, provincial, nacional, extranjera). Señala que "comprende las noticias de los sucesos que se han verificado en el tiempo transcurrido desde la publicación del número anterior". A pesar de este rasgo común reconoce distintas denominaciones, algunas de las cuales difícilmente entrarían en la "crónica" tal como se ha ido desarrollando, aunque sí en informaciones generales, pero que muestran las vacilaciones respecto de los géneros periodísticos entre las designaciones surgidas de la práctica y difundidas y el reconocimiento de los rasgos discursivos. Así, dice Jarrín: "también se denominan gacetillas, sueltos, recortes, reclamos, anuncios,... (183).

En cuanto a las revistas, las considera "publicaciones que constan de varios artículos relativos, por lo general, a diversas materias" (184). Las diferencia de los periódicos porque se dirigen a un destinatario más culto, aunque reconoce la existencia de revistas populares. Y en relación con el libro dice que las revistas "no versan sobre un solo objeto ni guardan la unidad, método y enlace, propios del organismo científico" ya que llegan a un público más amplio que el de los especialistas. Exige la competencia de los redactores en cada una de las materias que se abordan y, avizorando los requerimientos de la prensa industrial, dice que deben responder al imperativo de la actualidad para interesar a los lectores. Reconoce partes en las revistas, que implican tratamientos discursivos distintos: "una parte cientifica o literaria, otra bibliográfica y una tercera de variedades o crónica" (186).

Ilustra con el artículo de crítica, en lo cual se evidencia otra vez el peso de las representaciones dominantes y la preocupación religiosa del tratadista:

Estos se han de hacer sin apasionamiento hacia el autor, y con toda imparcialidad y exactitud respecto de la obra [...] Cuanto más importante sea la materia de una obra, tanto más rígido y circunspecto deberá ser el crítico y tratándose de obras religiosas, deberá tener presente que 'no a todo escritor le es dado encargarse de la causa de Dios'” (186).

Esta apertura a la heterogeneidad que anida en la prensa y sus dificultades en determinar sus diferencias se muestran en otros autores cuyas obras pertenecen al fin del período estudiado. Un caso interesante es Elementos de Retórica y Poética de Félix Sánchez Casado, que en las versiones anteriores, como la de 1881, no incluye el tratamiento de los géneros periodísticos pero sí lo hace en la de 1906, última expresión de nuestro corpus, en la que señala en la portada que ha sido "detenidamente corregida por Enrique Sánchez y Rueda". Posiblemente sea este el responsable del agregado. Es decir que, si bien en el transcurso del siglo se puede vacilar respecto de su ingreso o no a los manuales de retórica, ya a comienzos de siglo se considera que no pueden dejarse de lado el periodismo y sus diversos géneros. Cuando Sánchez Casado (1906) enumera los géneros advierte que va a tener en cuenta los "periódicos políticos", lo que es como hemos visto un gesto reiterado, y privilegia los textos argumentativos respecto de las noticias. Incluso el texto que propone como modelo es el artículo editorial. El listado, heterogéneo y que surge de la experiencia de lector y no de la práctica en el medio, lo que impondría algunas jerarquías, es el siguiente:

[...] artículo editorial; artículos científicos, artísticos, literarios, críticos, etc.; artículos de costumbres, revistas, reseñas, descripciones, discursos, polémicas, discusiones, controversias, comunicados o remitidos, correspondencia particular, servicio postal y telegráfico, noticias generales y gacetilla o conjunto de noticias locales; sueltos, miscelánea, folletín, noticias varias, asuntos o cosas del día, última hora; sección de espectáculos, boletín religioso, avisos oficiales y de corporaciones; sección de anuncios. (223) 
[...] Algunos periódicos añaden a los medios expositivos ya enumerados otras especialidades como las notas parlamentarias, el boletín meteorológico, el necrológico, el agrícola y comercial, el boletín de Bolsa, los telegramas bursátiles, las entradas y salidas de los buques en los puertos, etc. (225)

Caracteriza globalmente muchas de las entradas que ha establecido pero no se detiene en indicaciones normativas sobre el estilo, por ejemplo, o la extensión, o en el señalamiento de cómo se puede despertar el interés del lector, las dificultades o los límites del texto, como en la misma época lo van a hacer insistentemente los manuales periodísticos o como en relación con la polémica, por ejemplo, lo han hecho otros manuales. En algunos agrupamientos se evidencia la tensión entre el saber retórico y la plasticidad de un medio que se va afirmando discursivamente:

Son los discursos, polémicas, discusiones y controversias los debates sostenidos tal vez con otros periódicos sobre puntos que se refieren a la defensa de la propia causa, miras políticas, acontecimientos del orden actual, cuestiones parlamentarias y de propaganda, etc., en los cuales se procura dejar a salvo los principios que se sostienen. (224)

En relación con la noticia, que es género importante en la época, el comentario es escueto aunque efectúe deslindes:

Refiérense las noticias generales a los hechos ocurridos en el extranjero o en las demás provincias del Estado; mientras que la gacetilla o conjunto de noticias locales narra precisamente los acontecimientos de la vida real en el punto donde se publica el periódico. (224)

En cambio, es sensible a la importancia económica de la publicidad:

La sección de anuncios completa las miras propiamente utilitarias del periodismo y tal vez las de mayor resultado económico para las empresas y redacciones que cultivan. En dicha parte del periódico se emplea toda suerte de llamamientos y reclamos de la publicidad para dar a conocer ya las liquidaciones, baratos de géneros y ofertas de diferentes productos industriales, ya los medicamentos y sustancias que sirven para curar las dolencias [...] (225)

Es, entonces, al final del período cuando los tratados de retórica se interrogan más detenidamente sobre la diversidad genérica de la prensa haciendo ingresar las denominaciones ya generalizadas por el uso corriente. Pero la dependencia del sistema retórico les impide establecer criterios claros para efectuar las separaciones y caracterizaciones específicas y definir jerarquías. Los manuales de periodismo que comienzan a aparecer en la misma etapa lo harán a partir de la figura del lector, que impone exigencias a las que la escritura periodística debe atender.

\section{ConCLUSIón}

El indagar en las representaciones acerca de la prensa escrita en manuales de retórica, es decir en textos con un fuerte dispositivo normativo, del siglo XIX, etapa en la que se multiplicaron los medios gráficos, nos permite ver las dificultades de ingreso de nuevos objetos discursivos en un cuerpo textual caracterizado por su estabilidad y su permanencia.

Para que ese proceso se desencadenara era necesaria cierta sensibilidad de los autores de manuales a las transformaciones sociales de sus respectivos países y a la incidencia que en ellos tenían estos medios. Era necesario pensar que los destinatarios de esos manuales no eran solo los jóvenes estudiantes sino también, por un lado, aquellos que participaban en la vida política a través de la discursividad escrita, esencial en la formación de la opinión pública, en el desarrollo de instancias representativas y en la construcción de imaginarios colectivos; y, por el otro, aquellos que intervenían en el desarrollo de la sociedad industrial difundiendo los conocimientos entre un público cada vez más amplio en virtud del avance de la alfabetización (aunque esta tuviera su impulso mayor en la segunda mitad del XIX).

Por eso no es casual que Hermosilla y Gil de Zárate, dos personajes de intensa vida pública, introdujeran el periodismo en el manual, el primero focalizando el aspecto didáctico y el segundo, el político. Las 
representaciones asociadas con una dimensión o con otra se mantuvieron a lo largo del siglo, como testimonian manuales del último tercio. En numerosos casos conjugaban las dos y retomaban lo esencial de lo ya dicho o, incluso, copiaban la fuente indicándolo o no.

La dimensión didáctica fue la base de la representación, que permaneció mucho más tiempo, del magisterio de la prensa y del estatuto social que esta debía tener en la medida en que ilustraba a la sociedad en campos diversos. El señalamiento de la dimensión política de la práctica periodística, si bien tuvo importancia a lo largo del XIX, fue desapareciendo en la medida en que se comenzó a valorar la objetividad (lingüística) del medio. Esto no implicó que el periódico no acogiera la subjetividad política pero se consideraba que debía concentrarse en el editorial, heredero del artículo de fondo, y regulado por el dispositivo retórico que establecía la mesura, el respeto al otro, la regulación de las emociones.

Preguntándonos ahora no por qué se introducía el periodismo en los manuales de retórica sino por qué se lo hacía depender de campos ya recorridos como los de la elocuencia política o la prosa didáctica, debemos pensar en algo en lo que las teorías sobre las representaciones sociales han insistido: para integrar los elementos nuevos es necesario esquematizarlos pero al hacerlo intervienen los modelos mentales, los esquemas de pensamiento habituales, sobre todo cuando estos se afirman en una producción discursiva naturalizada. Si bien lo nuevo puede ser pensado en el marco de la retórica a partir de las categorías existentes, debemos señalar que estas también actúan como un obstáculo para aprehender el fenómeno en su diversidad y en su lógica productiva.

Para que esto pudiera ser superado era necesario que el autor de manual no solo participara en la vida pública y fuera sensible a las transformaciones sociales sino también que hubiera ejercido la escritura en diversos géneros, que viviera el proceso de profesionalización del escritor, que tuviera una imagen crítica del saber retórico y que formara parte de un grupo de intelectuales que tenía un contacto asiduo con la prensa, que se interrogara sobre ella y que pudiera contrastar, a partir del exilio o de las lecturas, diferentes modalidades nacionales. De allí que no fuera casual que desde un lugar periférico como era el Chile del siglo XIX se produjera el primer manual que se proponía recorrer los géneros periodísticos al mismo tiempo que reflexionar sobre las condiciones de producción y la materialidad de estos escritos.

Como vimos, Vicente Fidel López cumple esa función con su Curso de Bellas Letras de 1845. En él jerarquiza el discurso de la prensa asociando el diario y la revista al libro, dentro de los trabajos de crítica, valora a los que realizan esas tareas, muestra la tensión entre la necesidad de profundizar en los temas y la posibilidad que el medio abre de poder comunicarse con un público amplio. Señala cómo en los países hispanoamericanos, el diario, además de cobijar diversidad de géneros, tiene un carácter híbrido en la medida en que cumple también funciones de revista y libro. Asimismo, reconoce modalidades discursivas en el interior de un género, como el artículo de revista, ingresa la novela de folletín y permite vislumbrar el artículo de costumbres en el modelo de Larra. Si bien admite en el artículo periodístico político diversidad de tonos y estilos, recomienda, siguiendo el pensamiento ilustrado, que en la medida en que se tratan temas de interés de las naciones, que no se deje de lado el encadenamiento racional del discurso.

Tiempo después, aquellos que se interesan con mayor o menor intensidad por el reconocimiento de géneros periodísticos, van a reiterar la diferencia entre diarios y revistas, tratar de delimitar con cierto detenimiento los géneros, dar lugar a la crónica y a los textos informativos (retomando las referencias a sus vínculos con los géneros históricos) y, en algunos casos, mostrar la importancia de la publicidad. Sin embargo, no alcanza esta apertura mayor amplitud porque los autores están presos de los dispositivos normativos y de los marcos de reflexión retóricos. Será necesario cambiar de lugar para pensar, en su complejidad y en sus cruces genéricos, la escritura periodística. Lo harán aquellos que vivan las experiencias de las redacciones y de la expansión de la prensa industrial, que impone contemplar en el ejercicio profesional al lector, fuente importante del financiamiento de la empresa. 


\section{Bibliografía}

Arnoux, E. Narvaja de (2008). Los discursos sobre la nación y el lenguaje en la formación del Estado chileno (1842-1862). Estudio glotopolitico. Parte IV: Hacia la regulación estatal del espacio discursivo. Buenos Aires: Santiago Arcos.

Arnoux, E. Narvaja de (2015). Los manuales de estilo periodísticos para las versiones on line: las representaciones del lector y su incidencia en la regulación de discursos y prácticas, Circula. Revista de Ideologías lingüísticas, 2, 138-160. Número temático: W. Remysen, S. Schwarze y J. A. Ennis (dirs.). La mediatización de las ideologías lingüísticas: voz de autores y voz de lectores, Les Éditions de l'Université de Sherbrooke (ÉDUS).

Arnoux, E. Narvaja de, Blanco, M. I. y di Stefano, M. (1999). Las representaciones de la lengua y de la prensa en los manuales de estilo periodísticos argentinos. En E. Arnoux y R. Bein (eds.), Prácticas y representaciones del lenguaje. Buenos Aires: Eudeba, pp. 175-190.

Arnoux, E. Narvaja de (2017a). El disciplinamiento de la discursividad y sus desplazamientos en los manuales de retórica del siglo XIX destinados a la educación secundaria. En E. N. de Arnoux, I. C. Gutiérrez y V. Papalini. Procesos de subjetivación y control. Una mirada crítica a los procesos de disciplinamiento. Cali: Universidad del Valle, en prensa.

Arnoux, E. Narvaja de (2017b). Los manuales de retórica y los de urbanidad del siglo XIX: el control de las emociones como marca de distinción. Rétor, 7 (2), 110-134.

Arnoux, E. Narvaja de (2018). De lectores y géneros periodísticos: los textos normativos de fines del siglo XIX y comienzos del XX. En C. Marimón e I. Santamaría, volumen sobre Ideologías lingüisticas. Berna: Peter Lang, entregado.

Espiritusanto, O. y Gonzalo Rodríguez, P. (eds.) (2011). Periodismo ciudadano. Evolución positiva de la comunicación. Madrid: Ariel y Fundación Telefónica.

Ezama Gil, Á. (2014). Primeros datos sobre la presencia del reportero en la prensa española. Anales, 26, 167-186.

García Galindo, J. A. (2005). Estudios de periodismo. Los primeros tratadistas españoles. En J.-M. Desvois (ed.). Prensa, impresos, lectura en el mundo hispánico contemporáneo. Homenaje a Jean-François Botrel. Burdeos: PILAR, pp. 179-190.

García Tejera, M. C. (2006). El periodismo en los manuales decimonónicos de preceptiva literaria. En J. A. Hernández Guerrero (coord.). Retórica, literatura y periodismo: actas del V Seminario Emilio Castelar. Cádiz, noviembrediciembre de 2004, pp. 209-222.

Guillamet, J. (2003). Por una historia comparada del periodismo. Factores de progreso y atraso. Doxa Comunicación, (1), 35-56.

Mancera Rueda, A. (2011). El periodismo en las preceptivas literarias de los siglos XIX y XX, Dicenda. Cuadernos de Filología Hispánica, 29, 231-250.

Morales Sánchez, I. (1999). Teoría del artículo periodístico en la España del Siglo XIX, Estudios de literatura, (24), 145-155.

Morales Sánchez, I. (2000). Los manuales de retórica y poética: un espacio de discusión sobre los géneros literarios en la primera mitad del siglo XIX, Cuadernos de Ilustración y Romanticismo, (8), 167-175.

Palmer, M. (1983). Des petits journaux aux grandes agences. Naissance du journalisme moderne. París: Aubier.

Rodríguez Rodríguez, J. M. (2009). La clasificación del periodismo en las preceptivas retóricas y literarias del XIX español. Entre el desdén y la perplejidad. Textual \& Visual Media. Revista de la Sociedad Española de Periodística, (2), 235-246.

Rodríguez Rodríguez, J. M. (2016). Rasgos de la figura del periodista en los primeros tratados de periodismo en España. Hacia una identidad profesional (1891-1912). Revista de Comunicación, (15), 86-110.

Rivera, J. B. (1998). El escritor y la industria cultural. Buenos Aires: Atuel.

Salaverría, R. (1997). Aproximación a los orígenes de la preceptiva sobre escritura periodística (1840-1940). Comunicación y sociedad, 10 (1), 61-94.

Seoane, M. C. (1992). Historia del periodismo en España. Vol. 2: El siglo XIX. Madrid: Alianza. 
Sousa, J. P. (2007). Pesquisa e reflexão sobre jornalismo até 1950: a institucionalização do jornalismo como campo de conbecimento e campo cientifico. BOC (Biblioteca online de Ciencias de la Comunicación). Recuperado de: http ://www.bocc.ubi.pt/pag/sousa-jorge-pedro-pesquisa-e-reflexao-sobre-jornalismo-1950.pdf

\section{Fuentes Citadas}

Arpa y López, S. (1878). Compendio de Retórica y Poética. Cádiz: Imprenta de la Revista Médica.

Avendaño, J. de (1885) [1844]. Elementos de Gramática Castellana precedidos de unas ligeras nociones de Lingüistica y seguidos de algunas de Literatura, Retórica y Poética. Novena edición, corregida, aumentada y reformada por el autor. Madrid: Librería de Hernando.

Barros Arana, D. (1908) [1867]. Elementos de Retórica y Poética. Tomo III de las Obras Completas. Santiago de Chile: Imprenta Cervantes.

Campillo y Correa, N. (1875) [1872]. Retórica y Poética o Literatura Preceptiva. Madrid: Librería de D. Gregorio Hernando.

Castañeda, F. (1916) [1892]. Lecciones de Retórica o Literatura preceptiva. Cuarta edición revisada por el autor. Guatemala: Tipografía Sánchez \& De Guise.

Coll y Vehí, J. (1894) [1862]. Compendio de Retórica y Poética o Nociones elementales de Literatura. Barcelona: Imprenta Barcelonesa.

Cortejón, C. (1890). Curso razonado de Retórica y Poética con ejercicios prácticos y trozos escogidos. Barcelona: Imprenta de la Casa Provincial de Caridad.

García de La Madrid (1817). Compendio de retórica, sacado de los autores de mejor nota. Barcelona: Oficina de Brusi.

Gil de Zárate, A. (1842). Manual de literatura. Principios generales de Poética y Retórica. Madrid: Boix editor.

Gómez Hermosilla, J. (1841) [1826]. Arte de hablar en prosa y verso. Novena edición. París: Librería de Garnier Hermanos.

Herrera Dávila, J. (1827). Lecciones de Retórica y Poética. Sevilla: Imprenta de don Mariano Caro.

Jarrín, F. (1893). Retórica y Poética. Salamanca: Imprenta de Calatrava.

Jerez Perchet, A. (1901). Tratado de periodismo. Granada: El defensor de Granada.

López, V. F. (1845). Curso de Bellas Letras. Santiago de Chile: Imprenta del Siglo.

López de Vergara, J. N. (1858). Curso Académico de Elocuencia Española. Obra póstuma publicada por su hijo, Fernando López de Lara. Tenerife: Imprenta y Librería de Salvador Vidal.

Mainar, R. (1906). El arte del periodista. Barcelona: Sucesores de Manuel Soler.

Marroquín, J. M. (1935) [1882]. Retórica y Poética. Bogotá: Editorial Minerva.

Munárriz, J. L. (1815). Compendio de las lecciones sobre la Retórica y Bellas letras de Hugo Blair. Madrid: Imprenta de Ibarra.

Rodríguez, J. (1879). Lecciones elementales de Literatura. Córdoba: Imprenta del Eco de Córdoba.

Sánchez Casado, F. (1881). Elementos de Retórica y Poética, Madrid: Libreía de B. Hernando.

Sánchez Casado, F. (1906). Elementos de Retórica y Poética, décima edición detenidamente corregida por Enrique Sánchez y Rueda, Madrid: Librería de Perldo, Páez y C. y Librería de Luis Jubera.

Verdaguer y Callís, M. (1889). Sumario de Retórica y Poética o Literatura preceptiva. Logroño: Imprenta y Librería de El Riojano.

\section{NoTAS}

1 Solo indicaré las fechas de los textos del corpus en la primera referencia, salvo cuando sea necesario reiterarlo para una mejor comprensión.

2 Los resaltes en la cita me pertenecen. 